\title{
PRELIMINARY FIELD OBSERVATIONS OF THE CHILEAN EARTHQUAKE OF 3 MARCH 1985
}

\author{
David J. Dowrick
}

\section{ABSTRACT}

This paper is an initial appraisal of the effects of the $M=7.8$ earthquake centred near San Antonio, Chile, which occurred on 3 March 1985. The author arrived in Chile six days after the main shock and spent a week investigating as many aspects as possible. The earthquake caused heavy damage to a large area including the major cities of San Antonio, Valparaiso and Santiago, and resulted in 700,000 people being made homeless.

Damage to engineered structures appeared to be less than might be expected for an earthquake of this magnitude, but nonstructural damage was heavy. Eight or nine accelerographs recorded the shaking in different parts of the more heavily affected area and should help enrich the findings of the numerous valuable postearthquake studies which will be possible.

\section{INTRODUCTION}

At $7.46 \mathrm{pm}$ on 3 March 1985 a large earthquake shook central Chile, causing widespread damage in urban and rural areas affecting the principal cities San Antonio, Valparaiso and Santiago as well as many other smaller communities in an area exceeding 200 by 80 kilometres. The main shock has been assigned a Richter magnitude $M=7.8$ and two weeks after the event the official damage statistics included 177 people killed, 2,500 injured, 170,000 homes destroyed and 700,000 people homeless. Early estimates of the cost of the earthquake were set at \$US600 million, but some locals expected that this figure would be considerably exceeded. Considering the large amount of damage to houses the number of deaths and injuries was mercifully low. This has been attributed to the fortunate time of the earthquake which occurred during the evening promenading period when the local custom is for most people to walk about in the streets. Despite the large amount of adobe construction, there were a significant number of casualties in engineered buildings?

\section{SOME SEISMOLOGICAL ASPECTS}

Based on the uncorrected data, the peak horizontal ground accelerations varied between about $0.16 \mathrm{~g}$ and $0.75 \mathrm{~g}$ with vertical accelerations being in much the same range. There is a possibility that in one direction acceleration increased rather than decreased with distance from the source for a distance of sorne tens of kilometres. If true, this will pose some interesting questions about the nature and distribution of the rock layers in the transmission path.
The possibility of this earthquake being imminent occurred to one of the Chilean engineers because of a sudden drop of water level in his well, together with a cluster of microtremors. These phenomena happened at about the same time and shortly before the main event.

Together with its preshocks and aftershocks this major earthquake was recorded by a number of instruments belonging to the local network ${ }^{2}$. It appeared that accelerographs at at least nine stations triggered, the minimum expected yield being 18 horizontal and eight vertical components, and a possible maximum of three times this number of accelerograms. The available records should be sufficient to permit much valuable research to be carried out on important subjects such as focal mechanisms and attenuation.

The total duration of shaking recorded for the main event was 120 seconds, of which 40 seconds was "strong shaking". Preliminary assessment of the data showed that a multiple event had occurred. The first event in the series was of magnitude $M=5.3$ with a focal depth of 15 kilometres, and an epicentre located 30 kilometres offshore from Algarrobo, a coastal town between San Antonio and Valparaiso. Because of the overlapping of the two (or more) events in the sequence, the arrival times of the $P$ and $S$ waves and hence the epicentre for the main event was difficult to determine precisely, but the latter was located slightly further north some 35 kilometres from valuaraiso ${ }^{3}$. The results of the ensuir studies are to be awaited with interest.

The overlapping of the individual 
earthquakes within the multiple event also complicates the determination of their magnitudes. This is illustrated by the recording at Imperial College in London from which the apparent Richter magnitude of the main event was artificially high at $M=8$ while the body wave magnitude was $M=6.8$. This is a wider difference than normal between $M$ and $M_{1}$ caused by the overlapping of the events which enhanced the apparent magnitude of the main event.

Initial estimates of intensity of shaking also pose some interesting questions. Firstly the MM intensities in what was thought to be the epicentral area were relatively low for an earthquake of $M=7.8$, the maximum intensity probably being MM9, which was observed in one small area only, namely on the poor soil of downtown San Antonio. The relationship between the definitive focal mechanism and the isoseismals will hopefully help to explain this phenomenon.

\section{FIELD RECONNAISSANCE ARRANGEMENTS}

The author was in London at the time of the earthquake, and decided on 7 March to fly the next day to santiago with Edmund Booth from Ove Arup \& Partners' London office. After 24 hours travelling we arrived in santiago on the afternoon of Saturday 9 March. As damage was very widespread and travel arrangements initially uncertain we decided to be based in Santiago, travelling daily to different areas of interest.

We travelled mainly in our hire car, or in mini-buses provided and organised magnificently by the University of Chile or in cars of university staff or other visitors. We travelled and/or conversed variously with Chileans, Argentinians, Americans (the EERI team of seven), a Costa Rican and a German. The friendly sharing of news and views helped greatly in making the most of the visit.

On each of the seven full days spent in Chile, Sunday 10 to Saturday 16 inclusive, we were in the field, mostly travelling two hours or so each way to get to the daily zone of interest. To make maximum use of the daylight, we did not start for base till dark most nights, and consequently usually started dinner about $10.00 \mathrm{pm}$.

Everyone found this routine exhausting, and many of us suffered from the local "tummy bug" at some stage. However, such opportunities to learn from the real thing are not common, and the effort was well worth making.

\section{SEISMIC RESPONSE OF BUILDINGS}

\subsection{Adobe and Unreinforced Brick Buildings}

Adobe (mud brick) is used in Chile for many buildings including houses, farm buildings, light industrial buildings and modest churches. Naturally the pure adobe buildings were the worst affected and as the majority of the populace live in adobe houses, the high figures for homelessness mentioned above can be easily explained.

As has occurred in previous earthquakes, the older style of buildings framed with timber studs with adobe infill performed much better than pure adobe; while such buildings sometimes sustained severe damage, total collapses appeared to be rare. Even quite crudely detailedframing of almost any sort gave considerable protection to many other adobe buildings.

The beautiful 19th century Basilica del Salvador in Santiago, constructed of unreinforced brickwork, was very heavily damaged, which was particularly sad from a cultural point of view. It had sustained some damage in the 1906 earthquake.

\subsection{Reinforced Masonry Buildings}

Relatively little reinforced brick or block construction was observed, but one housing estate of flats made of reinforced brick was visited.

The Villa Santa Carolina in Santiago comprised three-storey blocks of 1984 construction all of which were heavily damaged (Figure 1). While the materials and workmanship appeared to be generally of good quality, the bricks had perhaps excessive vertical holes and the amount of vertical reinforcement was considerably less than would be required by the New Zealand code.

\subsection{Timber Buildings}

For a country with a large indigenous timber resource, it was surprising to find few buildings of timber construction, but not surprisingly there was apparently no significant damage to any but the crudest examples of this form of construction. The good performance of recently built weatherboard buildings of very light construction should help to promote the use of timber in Chile, and local engineers expressed interest in New Zealand experience and current research in this area.

\subsection{Steel Builaings}

Structural steelwork is also relatively little used. The few singlestoreyed industrial buildings identified had generally performed well. This could even be said of the three-pinned portal framed warehouse on the breakwater of San Antonio harbour, as this building had suffered considerable damage (without collapsing) due to excessive differential subsidence of the embankment.

\subsection{Reinforced Concrete Buildings}

Most of the more modern non-domestic buildings in the affected zone were made of in-situ reinforced concrete, of either shear wall or moment-resisting frame construction. These buildings exhibited 
a wide range of response in any given locality, including anything from being undamaged to being damaged beyond repair. Sixteen reinforced concrete buildings (or groups of similar buildings) were visited. The nature of the inspections undertaken in these visits of course did not permit definitive or complete determination of the causes of damage, but various damage mechanisms and contributory factors could be ascertained with reasonable certainty.

The eleven damage mechanisms observed in the primary members of these 16 buildings occurred in at least 27 instances, as set out in Table 1. It will be seen that 12 of these 27 instances involved shear failure and six involved compression failure, while only in three cases was tensile failure likely (items 6 and 7 of Table 1). Even if a deeper examination of these buildings altered the preceding numbers slightly, the vulnerability of reinforced concrete to shear and compression failures is underlined. As 12 of these 16 buildings were shear wall structures, and as the median date of their design was about 1967 the high incidence of brittle modes of failure is not surprising, a reaction enhanced by the relatively light shear reinforcement observed in damaged walls. However, the reason for the good performance of many other buildings when the above ones failed may warrant further examination, as the current Chilean codes apparently are not yet requiring much ductility ${ }^{2}$.

\subsection{Factors Contributing to Damage}

As well as the direct effect of ground shaking on the buildings discussed in the previous section, eight other factors were seen to have contributed to the level of damage as summarised in Table 2. The most common of these factors was poor structural form which occurred in four of the 16 buildings, and thus emphasises the importance of this aspect of design ${ }^{6}$.

One example of this factor was at the Villa Olympica in Santiago with the collapse (Figure 2) of the end bay of one of a series of similar buildings which otherwise performed moderately well. Two aspects of structural form seemed likely to have contributed to this local collapse. Firstly high asymmetry existed in plan layout because this building was rigidly connected to an adjacent building at the other end from the collapse, and secondly there was a soft storey effect at the collapsed end as can be seen from Figure 2 .

The earthquake apparently provided a spectacular example of topographical focusing of ground shaking at the canal Beagle housing estate at Viña del Mar. A number of discrete groups of similar blocks of apartments have been built in the same neighbourhood but on topographically very different sites. The buildings on the tops of steep hills (Figure 3) were heavily damaged (Figure 4) while those on flat or valley sites suffered little or no damage. It is to be hoped that fresh insights into this topic will be gained from analytical studies of wave propagation in models of this area.

Only one further factor noted in Table 2 will be commented on here, namely that of previous earthquake damage. Two of the 16 buildings visited had been redamaged in members that had been damaged in the 1971 earthquake and subsequently repaired. In the case of the Acapulco Building at viña del Mar (Figure 5), there was evidence of heavy rusting of reinforcement in the previously damaged zone, which raises the serious question of the likely effectiveness of repairs to damaged buildings.

\subsection{Non-Structure and Secondary Struc-}

To the author's mind at least, an important feature of the earthquake was the heavy damage to building components not affecting structural collapse. Enormous areas of windows were broken, often in buildings showing little sign of structural damage. Countless piles of masonry from infill walls lined the streets, again often outside homes or commercial buildings with little or no external sign of damage.

of the 16 concrete buildings discussed above, it is of interest to consider those having both modest (that is, repairable) structural damage and nonstructural elements. There were three such buildings and all had suffered heavy damage to infill walls, spandrels and glazing (Figure 4), none of which was separated from the structure. This, of course, would be expected in the momentresisting frame building, but the other two buildings had shear wall structures. Some investigation of the deformations in these latter two buildings might therefore provide further data on the degree of protection to non-structure provided by shear wall stiffness above.

Turning to secondary structural members, that is, those not affecting the resistance to overall collapse, as summarised at the bottom of Table 1 these were heavily damaged in six of the 16 concrete buildings visited. Four of these six buildings may be considered to be structurally repairable. It was thus found that heavy damage had occurred to both non-structure and secondary structure in a significant number of buildings which were structurally repairable. As was found in other fairly recent earthquakes, for example, Managua and San Fernando, the total cost of repair may be prohibitive for some of these structurally repairable buildings, largely because of damage to components other than primary structure.

It therefore appars that more study of the materials and construction details of non-structure and secondary structure could have valuable cost benefits at least in the broader terms of capital versus repair costs. 
TABLE 1 Nature of Damage Mechanisms Observed in 16 Reinforced Concrete Buildings* (Significant Damage Only)

\begin{tabular}{|c|c|c|}
\hline Member Class & Damage Mechanism & $\begin{array}{l}\text { Number of Buildings* } \\
\text { Where Mechanism } \\
\text { Observed }\end{array}$ \\
\hline \multirow{11}{*}{$\begin{array}{l}\text { Members of primary } \\
\text { frames resisting over- } \\
\text { all collapse of } \\
\text { a) building or } \\
\text { b) pedestrian bridges } \\
\text { between buildings }\end{array}$} & 1. Sliding shear in walls & 2 \\
\hline & 2. Diagonal shear in walls & 5 \\
\hline & 3. Diagonal shear in columns & 5 \\
\hline & 4. Bending compression - in walls & 3 \\
\hline & 5. Bending compression - in columns & 1 \\
\hline & $\begin{array}{l}\text { 6. Bending (comp or tens?) - } \\
\text { in columns }\end{array}$ & 1 \\
\hline & 7. Bending (comp or tens?) - in beams & 2 \\
\hline & 8. Axial compression in columns & 2 \\
\hline & $\begin{array}{l}\text { 9. Hammering across vertical } \\
\text { temperature/shrinkage joints }\end{array}$ & 1 \\
\hline & $\begin{array}{l}\text { 10. Hammering etc at bridges between } \\
\text { buildings }\end{array}$ & 3 \\
\hline & $\begin{array}{l}\text { 11. Failure at roof/wall connections } \\
\text { of dissimilar materials (exact } \\
\text { mechanism not known) }\end{array}$ & 2 \\
\hline \multirow{3}{*}{$\begin{array}{l}\text { Secondary members } \\
\text { not resisting overall } \\
\text { collapse }\end{array}$} & 12. Shear in columns & 1 \\
\hline & 13. Shear/bending in beams & 4 \\
\hline & 14. Bending in floors & 1 \\
\hline
\end{tabular}

* "Buildings" - Individual buildings or groups of similar buildings, the latter comprising housing estates of apartment blocks.

TABLE 2 Factors (Other Than Shaking) Contributing to Structural Damage to 16 Reinforced Concrete Buildings*

\begin{tabular}{|ll|}
\hline Factor & $\begin{array}{l}\text { Number of Buildings* } \\
\text { Where Factor Observed }\end{array}$ \\
\hline Poor structural form & 4 \\
Inadequate roof diaphragm & 2 \\
Falling chimney & 1 \\
Construction error & 1 (perhaps 2) \\
Gross underdesign & 1 \\
Differential settlement (including possible & 2 \\
Tiquefaction) & 1 \\
Previous earthquake damage (despite repair) & 2 \\
\hline
\end{tabular}




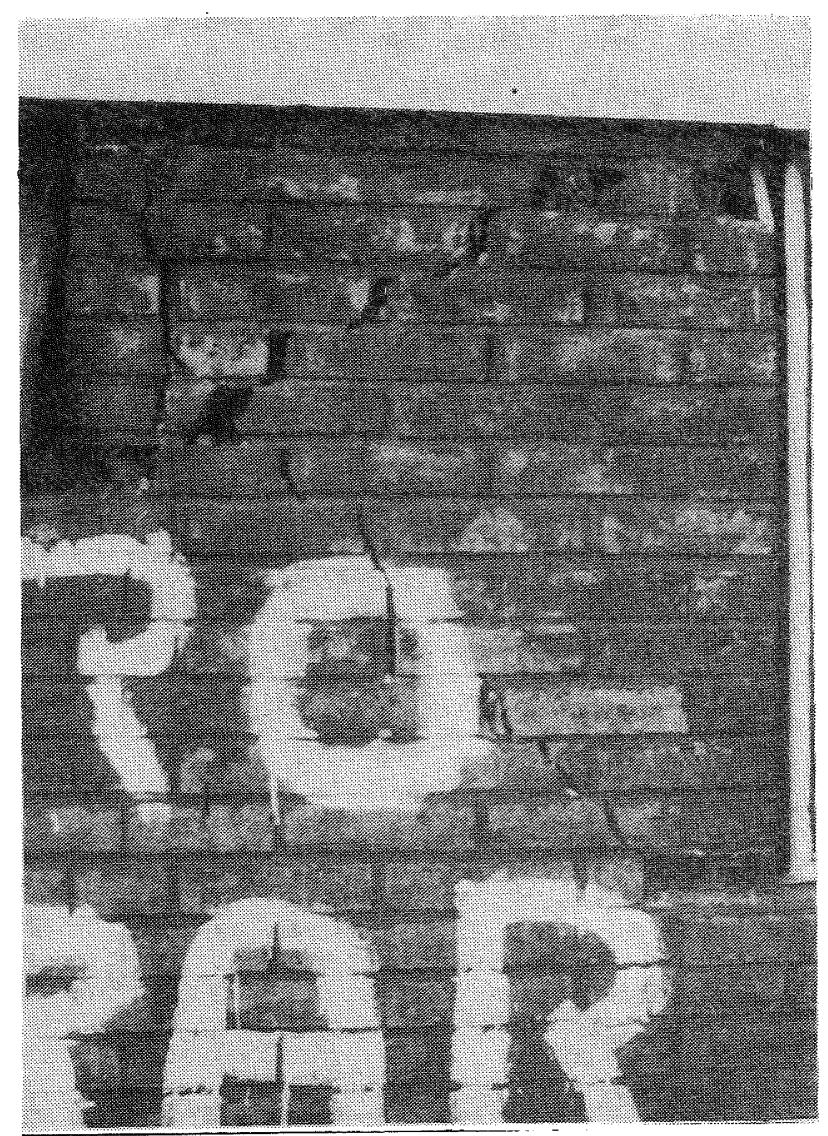

Figure 1. Shear cracks in reinforced brick walls, Villa Santa Carolina, Santiago.

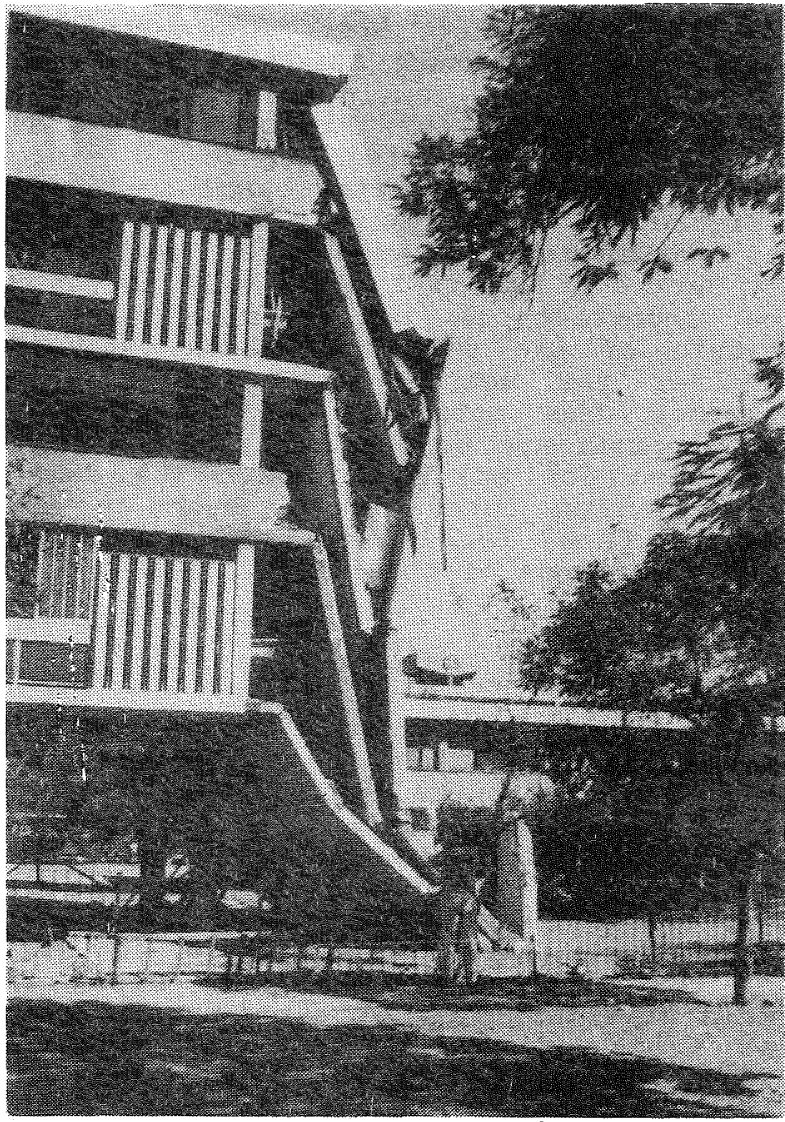

Figure 2. Collapsed end bay of reinforced concrete apartment block, Villa Olympia, Santiago.

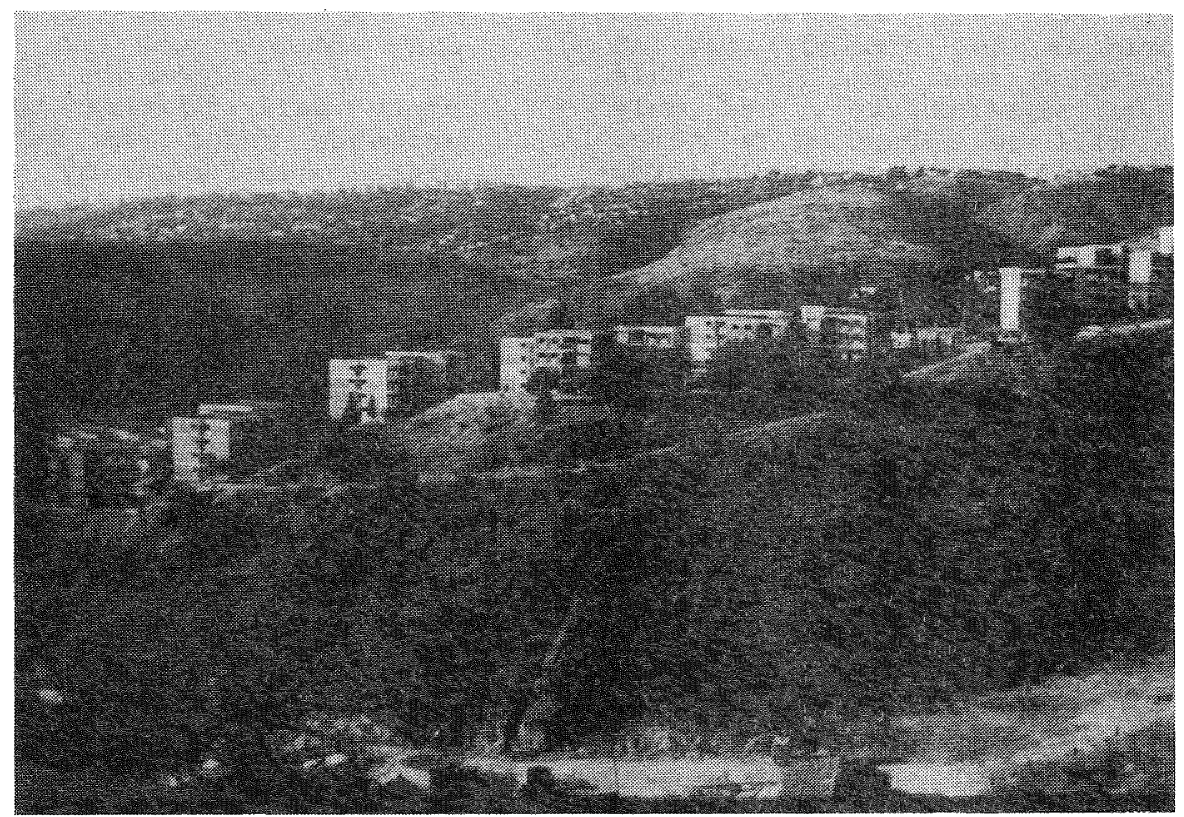

Figure 3. Topographical focusing appeared to have worsened the shaking for the buildings on this ridge, Villa Canal Beagle, Vina del Mar. 
The first principle of earthquake resistant design is to save lives. This has traditionally been approached by attempting to ensure that the structural frame does not collapse, while heavy damage to other items has been tolerated, albeit with increasing regard to danger from falling non-structural elements (Figure 5). An analysis of the causes of casualties in engineered structures by Durkin of the EERI team will therefore be important in ascertaining (a) the nature of the dangerous items, and (b) whether the methods used currently to protect the integrity of these items are appropriate to the level of integrity provided for the structure. The damage distribution noted above, such as that in the Canal Beagle apartments, stresses the importance of this topic.

\section{ROADS AND BRIDGES}

As usual in large earthquakes there was some disruption to road traffic as a result of the earthquake, due to debris from buildings, slips, subsidence and cracking of roadways and bridge failures. The level of initial disruption was not particularly great, most roads and streets being made passable within a few days of the earthquake. At least along the main arteries there were only a few slips on faces of cuttings as the hillsides were composed of stable rock and soil types. However, on the hillsides facing the ocean, localised slips had been sufficient to close a number of urban streets till higher priority works had been done. As might be expected, embankments gave more trouble, with a moderate amount of subsidence and tensión cracking of pavement surfaces, especially at bridge approaches.

Initially it was reported that about ten bridges had failed, but as the affected region was very, large this proved hard to substantiate, and only three bridges will be commented on here. Just south of San Antonio the Lo Gallardo Bridge (Figure 6) forms a major modern crossing of the Maipo River. A number of spans of this bridge collapsed, no doubt initiated by the failure of the piled piers in the permanent watercourse, the loss of this part of the deck then permitting larger longitudinal pier movements and the unseating of further deck spans. While foundation failure was the apparent cause of the loss of the piers, a detailed explanation will hopefully come from subsequent studies by Chilean engineers and the EERI team members.

A disused older single span reinforced concrete bridge which had been replaced by the above bridge fared no better, with the spans and piers over the permanent watercourse also collapsing, presumably also due to foundation failure of the piers.

Another bridge to suffer complete collapse was in the town of Palmilla, 45 kilometres west of San Fernando. This bridge was apparently damaged by the earthquake more than had been noticed and did not collapse until 13 March, ten days after the event. It was not reported what finally precipitated the collapse, but trucks heavily laden with the grape harvest were using this bridge.

Finally, the Concón Bridge on the coast road crossing of the Aconcagua River is worthy of mention. This concrete bridge crosses a wide shingle river bed and consists of many short spans, and would be similar in principle to many bridges in similar terrain in other countries including New Zealand. The tops of piers just below deck level had suffered substantial damage due to lateral and longitudinal bending moments, but apparently had been deemed still to have sufficient vertical load carrying capacity for the bridge to remain in service. No load restriction had been placed on the bridge which hopefully would not prove to have the same result as with the bridge at Palmilla.

\section{6. $\quad$ SILOS}

A group of wheat silos at the flour mill, Casablanca, were heavily damaged. These comprised reinforced concrete and bolted corrugated steel silos, the latter being in a state of collapse. The concrete silos were mostly built in the $1960 \mathrm{~s}$, and some had been damaged in the 1965 or 1971 earthquakes. Further damage occurred to the strengthened silos in this earthquake.

\section{SAN ANTONIO HARBOUR}

Large ground displacements often provide the most spectacular examples of earthquake damage, and the failure of the inner face of the breakwater at San Antonio was no exception (Figure 7). A considerable length of the concrete wall forming the quay had disappeared under the water and the associated subsidence of the adjacent paved area was enormous, causing massive damage to the quayside buildings and overturning ship-loading cranes. A few sand-boils were found in crevices in part of the subsided zone, but an initial appraisal did not find large scale liquefaction to be likely. However, the evident increase in pore water pressure in the embankment fill and the underlying sands may well have contributed to the quay wall failure and to the subsidence that seemed to have occurred in parts of the embankment not affected by the quay wall failure.

other quays within the harbour had not failed but there was no time to inspect them for signs of distress. However, their difference in behaviour may help in back-analysis of the breakwater collapse through comparative analyses.

\section{IIFELINES}

Although the author did not 
personally study lifelines it was evident that some serious disruptions to vital services had occurred. While the effect on electricity supplies seemed to have been moderate, water supplies were badly affected in many areas through broken water mains and damage to local header tanks. For example, two weeks after the earthquake half of Valparaiso's inhabitants were still without mains water due to the multiple leaks in a new trunk main serving a large part of the city. Ironically the rest of the city was served by older pipes.

Including hospitals in the definition of lifelines, it should be noted that at least two modern hospitals had to be evacuated due to heavy damage, namely the Claudio Vincuña Hospital in San Antonio and the Sermena Regional Hospital of Valparaiaso (Figure 8).

Obviously the loss of these hospitals with so many people injured by the earthquake would have greatly increased the problems of treatment and reinforces the need for extra protection against earthquakes for emergency facilities.

\section{CONCLUDING REMARKS}

Some preliminary thoughts arising from this reconnaisance visit were as follows:

There appeared to be less damage to engineered structures than might be expected from the average earthquake of Richter magnitude $\mathrm{M}=7.8$. be very structural damage seemed to non-structure may be appropriate for safety and cost reasons.

Heavier damage appeared to occur in localised pockets in some areas, and explanations for this should be sought from topographical, geological and structural origins.

The general standard of design and construction of engineered structures seemed good, although the need for the suppression of brittle failure modes was apparent in most of the damaged buildings inspected.

- Attempts should be made to learn from buildings and plant that performed well, as well as from those that were damaged.

The effectiveness of repairs to earthquake-damaged structures is a subject deserving more study.

- The Chilean engineers may well need to examine how strong the ground shaking of this event was in comparison with the design strength levels provided by their current codes, and what extra capacity (if any) the codes should provide for safety during expected larger earthquakes.

\section{ACKNOWLEDGEMENTS}

The friendly cooperation and assistance given to the author while in Chile is gratefully acknowledged, especially from The University of Chile in Santiago and the Technical University Frederico Santa Maria in Valparaiso, from which two institutions Professors $R$ Saragoni and $P$ Bonelli deserve particular mention.

\section{REFERENCES}

1 Durkin M E (1985) University of Southern California, Los Angeles - Personal Communication, prior to publication.

2 Saragoni G R (1982) "Earthquake engineering research program in Chile", Earthquake Information Bulletin, US Department of the Interior, 14, 1, pp 22-25.

3 Celebi M (1985) US Geological Survey, Menlo Park - Personal Communication.

4 Ambraseys $N$ N (1985) Imperial College, London - Personal Communication.

5 Bonelli P (1985) Frederico Santa Maria Technical University, Valparaiso - Fersonal Communication.

6 Dowrick D J (1977) "Earthquake resistant design", John Wiley and Sons, London, Chapter 4.

7 Gates J H (1985) California Department of Transportation, Sacramento Personal Communication.

8 "El Mercurio", Santiago, 15 March 1985, pp C1 and C5.

9 Henkel D J (1985) Ove Arup \& Partners, London - Personal Communication. 


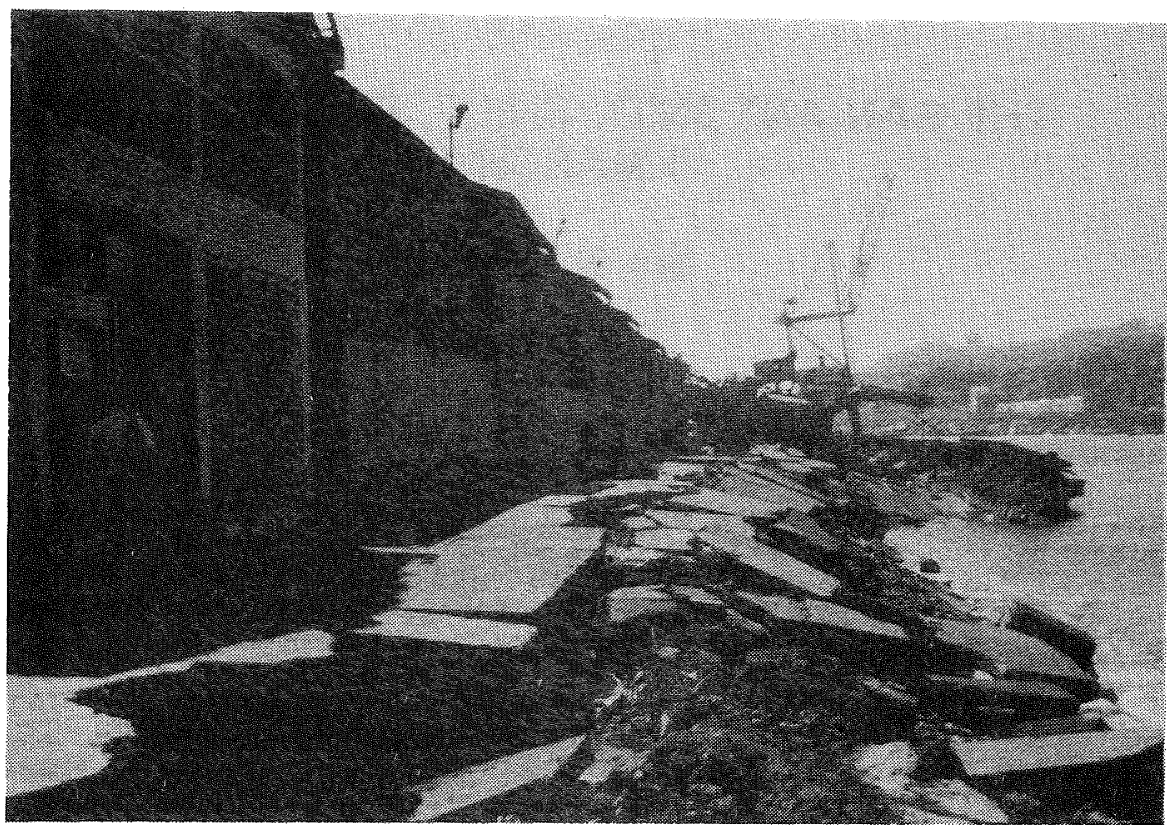

Figure 7. Quay side of breakwater at San Antonio harbour, showing collapsed quay wall and cracks.

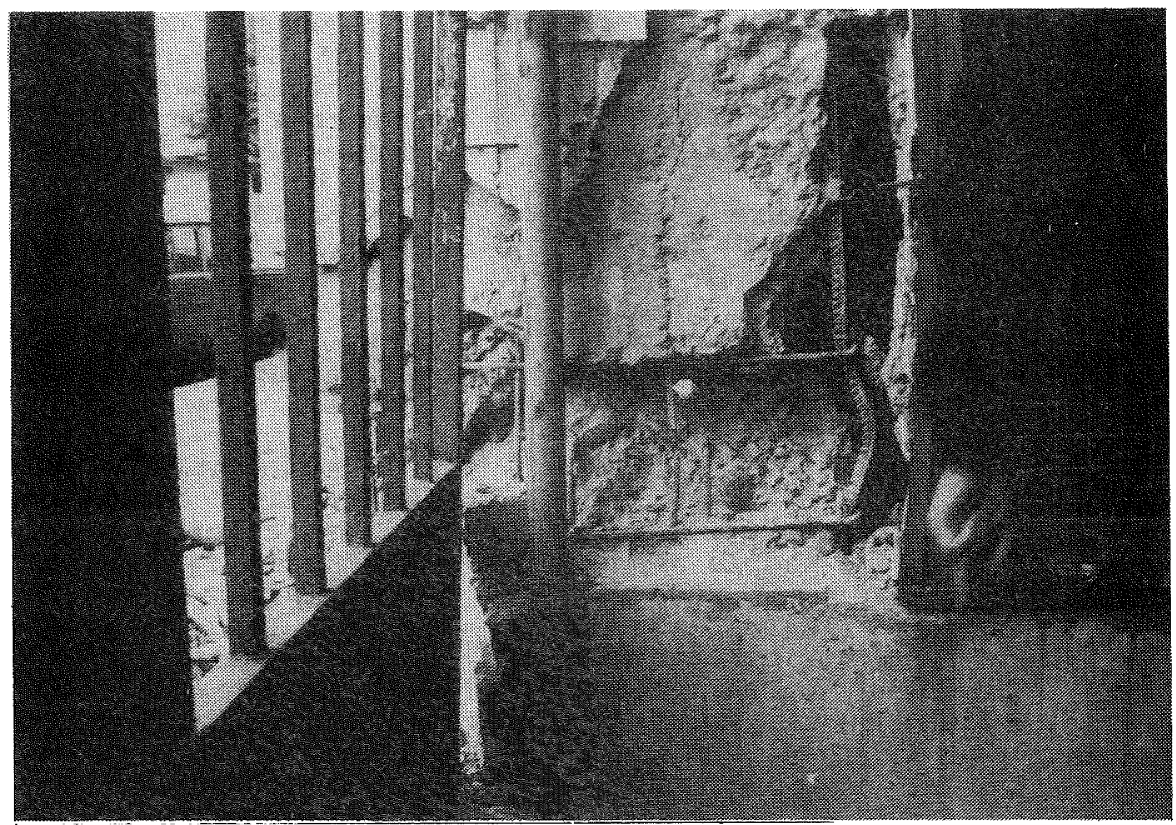

Figure 8. Compression failure of corner column of Sermena Regional Hospital in Valparaiso which had to be evacuated. 